\title{
A Study of ESP Teaching In the Era of MOOCs*
}

\author{
LIU Yu-jie \\ Jilin University of Finance and Economics, Changchun, China
}

\begin{abstract}
This paper makes a detailed analysis of Course Schedules (2013-2014) of College English in four universities of C9 League, which reveals that ESP courses are much less than EGP courses, even in the top universities in our country, and that the implementation of ESP teaching is hindered for many reasons. Therefore, based on the rapid development of MOOC and the one-size-fits-one guideline of college English teaching, the preferences of ESPMOOC have been illustrated, and the framework to practice trinity ESP teaching mode has been explicitly depicted. The mode refers to the combination of traditional classroom teaching, flipped teaching on aid of MOOC, and autonomous MOOC learning under the condition that ESP teaching group is elaborately set up and 2-band ESP teaching is preferably promoted.
\end{abstract}

Keywords: MOOCs, ESP, ESPMOOCs

\section{Introduction}

MOOCs (Massive Open Online Courses) is triggering a huge change in Chinese education reform. It breaks the stereotyped teaching mode in China and provides a stage for the fairness of education. The year of 2012 is named as the first year of international MOOCs for the sake of the establishment of three large-scale platforms for MOOCs: Udacity, Coursera, and edX respectively in February, April, and May. Tsinghua University and Peking University joined edX in May 2013, and Fudan Uniersity and Shanghai Jiao Tong University joined Coursera in July. Still in 2013 the first Chinese community of MOOCs created by Guokr.com was open to the public. The year of 2013 is taken as the first year of Chinese MOOCs. In September 2013 Guokr made an official agreement with Coursera to join in its universal project for translation. In October, Tsinghua University presented its first platform of MOOCs: Classroom Online. At the same time National Chiao Tung University in Taiwan, cooperated with Shanghai Jiao Tong University, Xi'an Jiao Tong University, Southwest Jiaotong University, and Beijing Jiaotong University, cultivating another online educational platform: ewant. In May 2014, icourse, coupled with NetEase developed a platform for Chinese University MOOCs, which can be applied by all the universities to the construction of online courses. On 24th September 2014, Tsinghua University presented its first MOOC about college English teaching: English Speaking and Listening Class in the Center of Universe, which is the guideline of the college English teaching reform.

This paper is intended to ease the controversy of EGP (English for General Purpose) and ESP (English for

\footnotetext{
* Acknowledgments: This paper was sponsored by the research foundation from the institute of educational science in Jilin Province, China (Grant No. ZD14071) and the research foundation from Higher Education Institute of Jilin Province in China (Grant No. JGJX2015C46).

LIU Yu-jie, Master, Associate Professor, College English Department, Jilin University of Finance and Economics.
} 
Specific Purposes) in college English teaching by providing ESPMOOCs (Massive Open Online Courses of English for Specific Purposes). We have analyzed the English curriculum in four elite universities, members of C9 League, in Beijing and Shanghai, focusing on the present situation of EGP teaching and the development of ESP teaching in higher education. Based on the availability of MOOCs in China, we proposed that it will be advisable to popularize ESP teaching with the aid of MOOCs platform, and we have explored the specific mode of ESPMOOCs.

\section{The Controversy Between EGP and ESP in College English Teaching}

In the past years, the orientation of College English Teaching in China has long been focusing on EGP and ESP. CAI Ji-gang claims in his paper that to extend basic College English Teaching to ESP teaching is the only way to cultivate the elites wanted by the enterprises (2004, p. 26). In May 2010 High-Level Forum on the achievements of computer-based teaching reform of National College English Teaching was held. It dealt with the issue of EGP teaching and the curriculum design of college English teaching. In September, CAI Ji-gang emphasized again that ESP should be the focus of college English teaching in the future. Still in the same year, Chinese Journal of ESP was initiated. In 2013, the first instructive document about college English teaching in the orientation of ESP drafted in July 2012, namely The Framework Reference for College English Teaching in Shanghai (Trial version), was approved by Shanghai municipal Education Committee. At the same time, the third High-Level Forum for Directors of College English Department was launched in Wuhai on April 11-14, 2013 where the Chairman of Steering Committee of College English Teaching cited the official document National Medium and Long-term Educational Reform and Development Program (2010-2020) and claimed that the principle of college English teaching is to guarantee the cohesion of English teaching in elementary and higher education, display the character of College English Teaching and combine with academic English (Wang \& Yao, 2013, p. 8). While YANG Feng and SUN Ling insist that the core of ESP lies in its feature of instrument, service, and academy, and firmly believe it is not determined by College English Department whether students learn ESP or not, because ESP learning is a market-driven English learning related to the need of society and individuality (2013, p. 2).

WEN Qiu-fang (2014) named the two parties of the controversy of ESP and EGP as "the party of substitution and the party of complementation; while Professor WEN advocates the latter. Like most of professors, she indicates that EGP and ESP do not actually conflict with each other. She proposes that all the universities in different level should provide students with two modules of college English teaching. They can take the courses based on their interest and need. Seemingly ESP teaching has become the indispensable task of English teaching in higher education.

\section{The Study of ESP and Current Situation of ESP Teaching}

QU Yun-hua did the research into ESP study in China and found that up to now papers about ESP teaching were not frequently created and most of them were only the description of some empirical summary or the introduction of ESP theory in foreign countries (1999, p. 75). It is hard to get access to the practical research on ESP curriculum construction, let alone the excellent ESP courses worth to be extended. We searched on line the resources with the keyword ESP and got 3,452 items of related references. On the perspective of numbers, the 
study has been improved; while most of them were dealt with after January 1, 2012. In the view of the content, it is also extended, some focusing on the adaptability of ESP teaching (YANG \& SUN, 2013), some discussing the problems and corresponding strategies of ESP teaching (GU, 2010, p. 25); some exploring the design of ESP textbooks and still a few of them doing the case study of ESP teaching (GUAN, 2014) and so on. Whereas the increase of numbers is not translated as the leap in quality of ESP teaching study in China. We made a detailed analysis of Course schedules (2013-2014) of College English in four universities of C9 League (Tsinghua University, Beijing University, Shanghai Jiaotong University, and Fudan University) and summarized the courses in terms of different features (based on the standards of course division in Framework Reference for College English Teaching in Shanghai ) (See Table 1).

Table 1

Course Schedules (2013-2014) of College English in Four Universities of C9 League

\begin{tabular}{|c|c|c|c|c|c|c|}
\hline \multirow[b]{2}{*}{$\begin{array}{l}\text { Category number } \\
\text { university }\end{array}$} & \multicolumn{3}{|c|}{ English for General Purpose（EGP） } & \multicolumn{3}{|c|}{ English for Special purpose (ESP) } \\
\hline & Basic courses & $\begin{array}{l}\text { Courses for } \\
\text { specific skills }\end{array}$ & $\begin{array}{l}\text { Courses for } \\
\text { cross-culture } \\
\text { communication }\end{array}$ & $\begin{array}{l}\text { Academic } \\
\text { English }\end{array}$ & $\begin{array}{l}\text { English for } \\
\text { specific subject }\end{array}$ & $\begin{array}{l}\text { Vocational } \\
\text { English }\end{array}$ \\
\hline TSinghua University & 5 & 11 & 19 & 5 & 4 & $\#$ \\
\hline Peking University & 4 & 13 & 15 & 1 & \# & \# \\
\hline $\begin{array}{l}\text { Shanghai Jiaotong } \\
\text { University }\end{array}$ & 4 & 11 & 17 & 2 & 7 & \# \\
\hline Fudan University & 3 & 9 & 8 & 8 & 3 & \# \\
\hline
\end{tabular}

Notes. * Based on Course schedules (2013-2014) of and the interpretation of the content of EGP and ESP by WEN Qiu-fang.

The column of number in Table 1 illustrates the number of segmentation of that category rather than the class number. For instance, in Tsinghua University college English courses consists of English course and basic English course, and English course is divided further into Level I, Level II, and Level III (four credits and 64 class hours each term); while basic English course has two levels (I \& II) (two credits and 32 class hours each term). The former is launched for students in School of Fine Art who have comparatively less command of English; and the latter is provided for all the undergraduate students eager to improve their English proficiency. Every segmented course may have more than one class to meet students' need.

\section{Exploration of the Differences}

Firstly, the four universities are characteristic on the credit and class hour. Tsinghua University grants students four credits for 64 hours classroom learning in College English each term, and the courses are in three levels designed for art major students only; while the English courses for all the other students eager to improve their English proficiency are endowed two credits after 34 hours classroom learning, and it is in two levels. In Peking University College English Courses consists of four-level classes of 36 hours for level one and of 34 hours for level two, three, and four ensuring two credits each term. Similar to it, Shanghai Jiaotong University provides also four-level college English courses; while the credits for each level are consistently three and class hours are 68. Fudan University, although designed four-level English courses, actually developed only Courses Level two, Level three, and Level four. What is more, credits for different levels are not the same. For Level three students can get four credits after 68 hour classroom learning in a term; while for Level two and four they can get only two credits, and the class hour is 34. In the four universities all the other EGP courses and ESP courses ensure two 
credits for about 32-36 hours English learning with the exception of Advanced English in Fudan University and Classics of Western Thoughts, Classics of Chinese Thoughts, and Legal English in Shanghai Jiaotong University endowing four credits for 68 hours learning in a term.

Secondly, in terms of the frequency of College English courses, the four universities differ dramatically in numbers of basic English classes. In Peking University and Shanghai Jiaotong University the number of basic English classes accounts for more than half of the EGP courses, the others are courses for specific skills or cross-culture communication while in lower proportion. In Tsinghua University and Fudan University, compared with other EGP courses, basic College English classes account for a small part, but academic English classes are also not in a large number.

\section{Interpretation of Similarities}

Although the four universities really differ in the name and frequency of basic College English courses and the granted credit for each course, all of them still attach much importance to EGP teaching. In terms of the category of EGP and ESP, the number of EGP courses are extremely larger than that of ESP, and the importance and inevitability of EGP is revealed without doubt. What is more, compared with academic English, the English courses for a specific subject are less provided. WEN Qiu-fang claims that Subject-based English is supposed to be given by academic professors, such as biology English, computer English, chemistry English and so on (2014, p. 6). In fact, the four universities really developed such kind of courses in specific college, but not in the Department of College English. These courses are given in English only or bilingually, which may not be the same as Subject-based English, actually, are much superior to it. These kinds of courses are mainly about the academy of science, economic management, and law. Most of them are developed by academic teachers, while they are named differently, such as Academic English and References for Macro-molecule major students, English for Science and Technology for Science and Technology of Electronic Information major students in Fudan University and academic English provided by the Department of Environment and English News established by the Department of Journalism in Tsinghua University. All of these are optional courses. Apart from the English courses targeted on specific subjects, the four universities are pushing the development of courses given in English only or bilingually. Presently, these courses are more popular than the academic English courses, because they are based on academic knowledge and under the scope of ESP. These courses are mostly required courses given by academic teachers majoring the subject, and the students needs to have a good command of English to take the courses.

\section{Problems and Reflections}

It is not deniable that in higher education ESP is more and more concerned, thus universities in different level are paying much more attention on the development of varieties of English courses, according to their teaching equipment, qualification of English teachers, and the background English of students, mainly to facilitate students to improve their ability to use English to communicate and ensure that with the aid of English students can be more competitive in job market. This is undoubtedly the destination of College English education and destined product of economic globalization. Whereas the research on the English courses presented by four prestigious universities reveals that even if the top universities with excellent faculties and students have not yet canceled basic College English courses, namely EGP teaching, and what is more, EGP accounts for a large part. 
YANG Feng and SUN Ling proposed that ESP teaching in higher education can only be subsidiary and optional, and also with the restriction of specific conditions and different periods (2013, p. 3). This happens to be consistent with what we have found in study.

Accordingly, the present situation of ESP teaching in different universities can be predicted, which implies that it is a long way to see the transformation from EGP to ESP in most universities as CAI Ji-gang has appealed (2011, p. 615 ). In the four universities, Fudan has eight academic English courses about science and technology, social science, literature, history, and philosophy and so on, topping any other three ones. CAI Ji-gang mentioned, when he recommended his new textbook An Integrated Academic English Course, that it will be a failure or neglect if undergraduates are not required to learn academic English in universities. However, as far as the fact we have found is concerned, it is far from realization. At the same time, we have to reckon on its appropriateness. At least we should not set only one standard for all the students in higher education. Probably, all students are eager to cultivate ability to search for English materials and get acquainted with the leading research findings in the world, but it is impossible that all students have a good command of English to learn academic English. Therefore, the core of College English teaching should be the complement of EGP and ESP, and it should provide the students with more effective learning resources under the present situation.

\section{The Basic Strategies of ESPMOOCs}

The first strategy of ESPMOOCs is to set up a specialized team of ESP teaching. The development of ESP teaching is determined by the qualification of teachers. To be a competent ESP teacher means that the teacher has to be both specialized in English and academic knowledge. He has to be able to transmit academic knowledge , explain academic terms, and analyze practical cases in English. To set up a specialized team of ESP teaching will motivate teachers to share information and communicate with each other and cultivate excellent course of ESP. Up to now, no any university has a specialized group of ESP teaching in spite that much importance has been attached to it. Fudan University has five modules of English teaching. They are comprehensive English courses, specialized skills of English, academic English, English courses about cultures, and second foreign language. These teachers do not only teach ESP courses, and they have to manage some EGP courses. In Peking University the Department of College English is attached to the school of Foreign Language assuming the responsibility of establishing a platform course of College English teaching. With the guidance of the national syllabus for college English teaching, all the teachers in the department work together to focus on the skill training of comprehensive English. They initiate basic English courses and a series of specialized and optional English courses. Tsinghua University has two studying groups of college English teaching and optional English courses. Shanghai Jiaotong University has four studying groups of college teaching attached to School of Foreign Language. All the information reveals that the four prestigious universities have no a specialized group for ESP teaching mainly focusing on the development of ESP courses. To appoint some qualified teachers to study ESP teaching will benefit the specialization of ESP teaching, the regulation of ESP teaching modes and the promotion of ESP teaching.

\section{To Refine the Plan of Two-Stage ESP Teaching}

With the improvement of MOOCs provided by the universities all over the world, the students who have the desire to learn English for special purpose will have more resources to refer to and get easily access to be 
acquainted with excellent teachers. On the condition that we can not popularize ESP in all the universities as CAI Ji-gang has proposed, to create ESPMOOCs will be a feasible way to meet the needs of students in different levels. Language learning is a gradual process, therefore without a solid foundation, no student can learn English in an advanced level. WANG Shou-ren and WANG Hai-xiao put it that basic English, namely English for general purpose is the basis of advanced English; and with no a good command of basic English, students can not catch up the flow of ESP learning (2011, p. 3). That means most of college English teachers should still focus on EGP teaching firstly to help students to improve their English proficiency and thus they can be competent to learn ESP courses which may be provided on the MOOC platform.

With the aid of national platform of MOOCs, to establish ESPMOOCs will be an ideal strategy to meet the students' further demand for ESP learning under the present situation of college English teaching; and the scarcity of ESP teachers will not be a hinder any more. ESPMOOCs will be the destination of college English education. Firstly, students will be placed to different classes based on their English background. The excellent students will get the opportunity to learn ESP after entering the university. The courses will be developed by the ESP studying group purposely. ESP courses consist of two-stage classes, preliminary and advanced classed. All the students qualifying ESP courses are required to sign up for them and advanced ESP courses will be optional ones for the advanced students (See Figure 1).

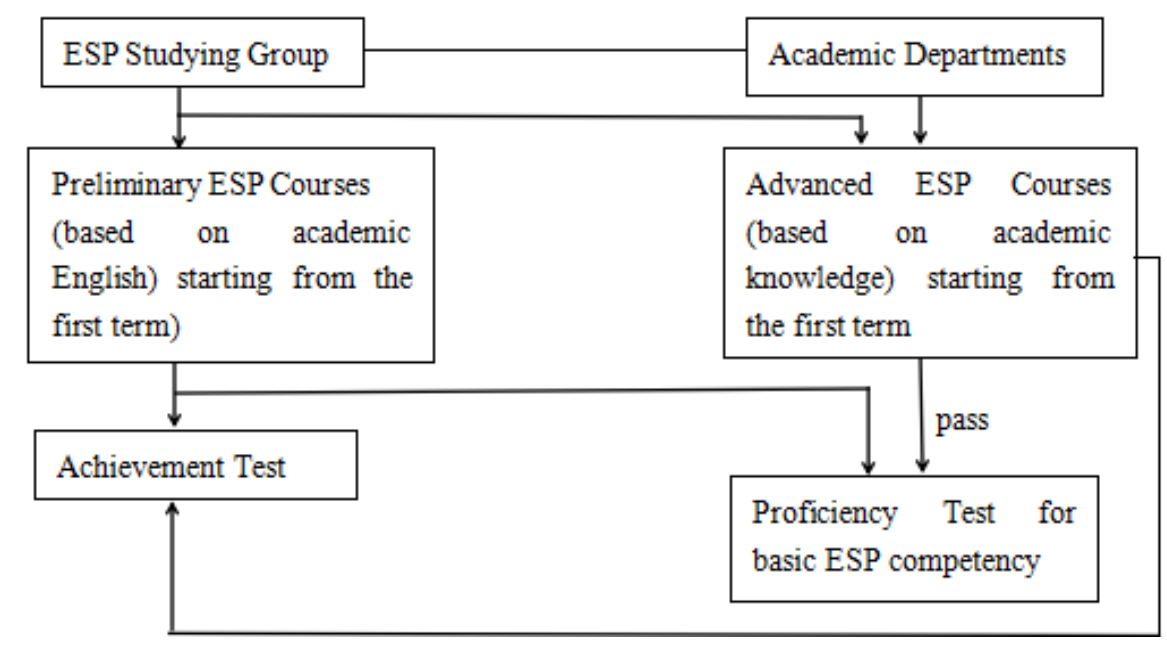

Figure 1. Two-stage ESP teaching module.

\section{To Practice Trinity ESP Teaching Mode}

The trinity ESP teaching mode means a combination of traditional classroom teaching, flipped classroom teaching, and autonomous study in a way of MOOC.

Specifically, preliminary ESP courses will be based on broad knowledge of academic English, and performed by teachers in the Department of College English Teaching. An Integrated Academic English Course by CAI Ji-gang can be used as a textbook to make the teaching plan. The class hours and the classroom activities can be adapted timely according to students’ English background and learning ability. The members of C9 League and universities which lead the development of ESP teaching can extend ESP courses as well as ESPMOOCs to provide a platform for students who are eager to learn ESP and push the further development of ESP teaching in higher education. 
Advanced ESP courses are based on specific academic knowledge, while focusing on English learning. They may be carried out by both of the teachers from ESP Studying Group and those from the others departments. Students may sign up for the courses related to their major, and usually have to complete learning within two terms. Advanced ESP classes may diversify in its teaching modes on the basis of students' proficiency in English and their majors. It is also advisable to develop flipped classroom teaching with the aid of MOOC platform. At the beginning of each term, teachers will make a learning plan and teaching objectives, and assign students some tasks to enhance them to study autonomously after class. While in the classroom students will be encouraged to extend seminars and practice critical thinking. By learning in this way, students will spare themselves much more time to improve their English proficiency and ability of critical thinking which will benefit them in the future. What is more, teachers may facilitate the competent students with explicit objectives and desire for international research to take appropriate MOOC to experience autonomous on-line learning. The courses may be recommended by teachers who will also be ready to answer students' questions and supervise and remind them of keeping up the work flow. At the end of the term, there will be an achievement test for students. Only those who pass the exam can obtain credits.

\section{Conclusion}

The landscape of ESPMOOCs will contribute to the ease of the controversy between the need of ESP teaching and the scarcity of qualified ESP teachers. It conforms to the broad view of education which infers that education is a diversified, comprehensive, and open system with the characteristics of lifelong extension, easy access, high efficiency, good quality, and rich contents. The view will make up the shortcomings of traditional classroom education, motivate the integration of higher education, realize the objective of sharing the educational resources, and promote the balanced development of higher education. MOOC learning can stimulate the students to be enthusiastic about autonomous study. After all, the ability to learn autonomously is the momentum of high quality education. Eduard Spranger, German educator, says that the ultimate aim of education is to provoke learners' creativity and wake them up in the sense of life and value, but not only to transmit knowledge. Therefore, the core of college English teaching is how to awaken students' momentum to learn English autonomously, how to motivate excellent teachers to exert their potential, and how to make full use of information and communication technology to develop ESPMOOCs and establish a national ESP class. This may be the only way to satisfy the students with the diversified professional needs in English learning.

\section{References}

CAI, J. G. (2004). ESP and the direction of college English teaching. Foreign Langugage World, 2, 22-28.

CAI, J. G. (2010). Reflections on the reorientation of English language teaching in higher education. Foreign Language Teaching and Research, 4, 306-308.

CAI, J. G. (2011). A study of the objective of college English teaching in mainland China from the perspective of the College English curriculum of the universities of Hongkong. Foreign Language Teaching and Research, 4, 609-617.

CAI, J. G. (2012). A way out for EFL at tertiary level education in mainland China. Shanghai: Press of Shanghai Jiaotong University.

CAI, J. G. (2013). Misunderstanding and prejudice: Barriers to the development of ESP in China. Foreign Language Teaching, 1, 56-60.

Candlin, C. (1987). Towards task-based language learning. In C. Candlin and D. Murphy (Eds.), Language learning tasks. Englewood Cliffs, NJ: Prentice-Hall. 
Curriculum Instruction of TSinghua University. (2013-2014). Retrieved from http://www.tsinghua.edu.cn/publish/newthu/newthu_cnt/education/pdf/201441.pdf

Curriculum Schedule of Beijing University. (n.d.). Retrieved from http://dean.pku.edu.cn/pkudean/course/kcbxs.php

Curriculum Schedule of Fudan University. (n.d.). Retrieved from http://www.jwc.fudan.edu.cn/68/ a5/c3167a26789/page.htm

Curriculum Schedule of Shanghai Jiaotong University. (n.d.). Retrieved from http://electsys.sjtu.edu.cn/edu/lesson/LessonQuery.aspx

GU. Zh. Zh. (2010). Analysis of current ESP teaching and coping strategies. Computer-assisted Foreign Language Education, 5, 25-29.

GUAN, J. J. (2013, November 18). MOOC: Can it topple the flow of education? Guangming Daily, (016).

GUAN, X. H. (2014). An investigation of extended curriculum courses of College English based on ESP Theories in a local university. Contemporary Foreign Languages Studies, 3, 33-37.

Haggard, S. (September 20, 2013). The maturing of the MOOC: Literature review of massive open online courses and other forms of online distance learning. Retrievd from https://www.gov.uk/government/uploads/system/uploads/attachment_data/file/240193/13-1173-maturing-of-the-mooc.pdf

QU, Y. H. (1999). A study of teaching the specialized reading courses in College English. Journal of Zhejiang University (Humanities and Social Sciences), 3, 74-79.

WANG, Sh. R., \& WANG, H. X. (2011). On the state of college English teaching in China and its future development. Foreign Languages in China, 5, 4-11.

WANG, Sh. R., \& YAO, Ch. H. (2013). Some thoughts on English for academic purposes (EAP) teaching. Foreign Languages in China, 5, 4-10.

WANG, Y. (2011). On the principles for compiling ESP textbooks. Foreign Languages in China, 2,75-81.

WEN, Q. F. (2012). Characteristics of challenges for College English from the perspective of curriculum theory: Problems and suggested solutions. Foreign Language Teaching and Research, 2, 283-292.

WEN, Q. F. (2014). Debate on teaching ESP or ESP in College English: Problems and suggested solutions. Foreign Languages and Their Teaching, 1, 1-8.

YANG, F., \& SUN, L. (2013). Some reflections on ESP-oriented college English teaching in China. Foreign Language Learning Theory and Practice, 3, 1-6. 